\title{
Health Care Service Quality and Its Impact on Patient Satisfaction "Case of Al-Bashir Hospital"
}

\author{
Rula Al-Damen ${ }^{1}$ \\ ${ }^{1}$ School of Management, Amman Arab University, Amman, Jordan \\ Correspondence: Rula Al-Damen, School of Management, Amman Arab University, Jordan Street, Amman, \\ Jordan. E-mail: aldamenrula@yahoo.com
}

Received: July 14, 2017

Accepted: August 8, 2017

Online Published: August 12, 2017

doi:10.5539/ijbm.v12n9p136

URL: https://doi.org/10.5539/ijbm.v12n9p136

\begin{abstract}
This study aimed to measure the impact of perceived health care service quality on patient satisfaction at a major government hospital in Jordan. For this purpose, the study developed an instrument based on modified 'SERVQUAL' using five service quality dimensions, namely: empathy, tangible, reliability, responsiveness and assurance. A survey was conducted to collect data with a total of 448 outpatient participants. Statistical techniques such as descriptive and inferential statistical techniques were employed to test the hypotheses. Results show that there is an impact of perceived health care service quality on overall patient satisfaction. Reliability had the most influence, followed by empathy and assurance. The study provided a set of recommendations.
\end{abstract}

Keywords: Service Quality, health care service quality, perception, SERVQUAL, Patient satisfaction, AL-Bashir Hospital

\section{Introduction}

Service quality has become an important topic in view of its significant relationship to profit, cost saving and market share. The interest in health care service quality is increasing. There is a growing consensus that patient satisfaction is an important indicator of health care quality and many hospitals are searching for ways to change the delivery of patient care through quality improvement initiatives.

Jordan is a country that has limited natural resources, low middle-income rates and high population growth rate. Jordan's economy is service-oriented, where the services sector constitutes for 67 percent of Jordan's GDP, while the combined contribution of industry, agriculture, mining, construction, water and electricity does not exceed 33 percent of the GDP (Alfanek, 2017). The health sector in Jordan consists of service providers (public, private, international and charity sectors) and councils and institutions working on the development of health policy.

Jordan has quite an advanced healthcare system. The country was ranked by the World Bank to be the number one healthcare services provider in the region and among the top five in the world (Health in Jordan, Wikipedia). There were 106 hospitals in Jordan in 2013 with a total capacity of 12,081 beds. MOH hospitals accounted for $38 \%$ of these ( 4618 beds). The private sector has a total of 3,998 beds ( $33 \%$ of the beds in Jordan) (The National Strategy for Health Sector in Jordan 2015- 2019).

Jordan has witnessed development in the field of health, especially in the establishment of public and private hospitals. The Ministry of Health, since its establishment in 1951, has taken all necessary measures and procedures continuing to provide medical and nursing services at acceptable level and with high efficiency in the affiliated hospitals.

Al-Bashir hospital is the largest governmental hospital in Jordan and was established in 1954. It provides medical care to government employees and their dependents, underprivileged families in Amman, and patients who are referred from healthcare centres in other parts of the country. It has up-to-date technology and is serviced by knowledgeable doctors. Hospital management aims to provide high quality health services and medical education, design to meet the needs of our community. The hospital vision is to transfer hospital into a leading institution in promoting health services and medical education for the community that they serve. Currently, it is equipped with 1,150 beds \& has 3,200 government employees (MOH statistics, 2017). The 
upgrading of the quality of services provided in public hospitals is a demand from hospitals management, health workers and patients at the same time.

However, like many other public healthcare systems around the world, the public hospitals face its share of problems. A major challenge for the public hospitals is to meet the growing expectations and demand for health services due to population growth, increases in cases of chronic health condition and the presence of refugees in the country. In addition to the expected rise in the proportion groups of young people and the elderly, rising healthcare costs and the increasing rate of brain drain mainly to Gulf countries due to low salaries, lack of incentives and regulations, and long working hours (Ajlouni, 2010).

Moreover, since, the ministry of health operates 38 percent of all hospital beds in the country and upgrading the quality of services provided in public hospitals is a demand from hospitals management, health workers and patients at the same time. Examining perceived health service quality in government hospitals and its impact on patient satisfaction is needed. With this background, the objectives of this study is: - to examine the impact of perceived service quality on patient satisfaction at Al-Bashir hospital, and to determine which dimension of the 5 has the greatest impact on overall patient satisfaction

\subsection{Problem Statement and Its Elements}

The quality of health care services has been the subject of constant interest among researchers and health institutions. To date, and despite the fact that many Jordanian hospitals began to adopt different quality improvement initiatives in the last two decades, the literature on patient perception about the quality of health services is still limited (according to researcher knowledge), especially in the public sector. This research tries to fill this gap by empirically investigating the impact of healthcare service quality on patient satisfaction at Al-Bashir Hospital form the point of view of patients.

\subsection{The Research Questions That Guided This Study Are}

1.2.1 To what extent health service quality dimensions are implemented at Al-Bashir Hospital from the patient's perspective?

1.2.2 What is the degree of overall patient satisfaction at Al-Bashir hospital from the patient's perspective?

1.2.3 What is the impact of health service quality on patient satisfaction at Al-Bashir Hospital from the patient's perspective?

1.2.4 Are there any differences in patient perceptions of health service quality dimensions due to demographic variables (gender, age, education, income and residence).

\subsection{Research Hypothesis}

(H01): There is no statistically significant impact at $(\alpha \leq 0.05)$ of health service quality (Reliability, Responsiveness, Tangibles, Assurance, Empathy) on patient satisfaction at Al-Bashir hospital.

(H02): There are no significant differences at $(\alpha \leq 0.05)$ in patient perceptions of health service quality dimensions due to demographic variables (gender, age, education, income and residence).

\subsection{Research Model}

The research model was developed by the researcher employing a modified SERVQUAL model which has been developed by Parasuraman et al. (1988). This study includes five service quality dimensions: Reliability, Assurance, Tangibles, Empathy and Responsiveness, and assessed by 22 items. Overall, customer satisfaction was measured using 6 items. The research framework can be seen below:

\section{Independent Variables}

Health Service Quality Dimensions
Dependent variables

Patient Satisfaction

Overall Patient satisfaction

Figure 1. Research Model 


\subsection{Operational Definitions}

Health care service quality: - services provided in Al-Bashir hospital whose characteristics and features meet or exceed patient's needs and expectations

Perceived health care service quality: - out patients' opinion or judgment of quality of service delivered by outpatient clinic at Al-Bashir hospital.

Reliability: The ability to perform the promised health care service dependably and accurately

Assurance: The knowledge, and courtesy of Al-Bashir hospital employees as well as their ability to inspire trust and confidence

Empathy: The provision of caring, individualized attention to outpatients

Responsiveness: The willingness to help out patients and to provide prompt service

Tangibles: The appearance of physical facilities, equipment, personnel and communication materials

Overall Patient satisfaction: - is a measure of the extent to which outpatient is content with the healthcare services which they received from al-Bashir hospital.

\section{Literature Review}

The impact of service quality on customer satisfaction has been the subject of constant interest among researchers. In this study, the reviewed literature is organized and classified along two main areas: theoretical concept and previous studies.

\subsection{Theoretical Concept}

\subsubsection{Service Quality Concept and Measures}

Service quality has become an important topic in view of its significant relationship to profit, cost saving and market share. Service quality is difficult to measure due to its characteristics include intangibility, heterogeneity and inseparability. Definitions of service quality hold that this is the result of the comparison that customers make between their expectations about a service and their perception of the way the service has been performed. In literature several frameworks for evaluating the quality of care have been proposed. In the 1980's many specialist suggested that service quality is a two dimensional variables (lithenin and lethinen (1982) \& Gronroos (1983). Lehtinen gave three broad dimensions of service quality, physical quality, interactive quality and the corporate image. Grönroos proposed the concept of service quality whereby service quality consists of two dimensions: technical quality and functional quality. Gronroos also emphasized the importance of corporate image in the experience of service quality. Berry gave two dimensions, outcome quality and process quality. Berry, Parasuraman and Zeithmal (1985) concluded that quality of a service depend on the service delivery procedure and does not depend exclusively on the outcome service. Through interview and focus groups developed a model of 10 dimensions tangibles, reliability, responsiveness, competency, courtesy, assurance, credibility, security, access, and understanding. Later in 1988, Parasuraman et al. reduced these ten dimensions into five dimensions. Cronin and Taylor (1992) developed the SERVPERF. It is a modification of SERVQUAL, uses the same categories to assess service quality, proposing 22 performance e related statements instead of 44 expectations and performance related statements. The SERVPERF measures quality as an attitude, not satisfaction. However, it uses an idea of perceived service quality leading to satisfaction. But it goes further, and connects satisfaction with further purchase. Teas (1993) model measures service quality as the gap between perceived performance and ideal performance instead of customer's expectations as in SERVIQUAL MODEL. Rust and Oliver (1994) added "service environment" as a new dimension to Gronroos model. Dabholkar, P A., et al., (1996) argued that retail services are different from pure services that make SERVIQUAL inapplicable. A more comprehensive and hierarchal second order model consisting of 28 items scale 17 came from SERVIQUAL and 11 items from researchers' review of literature. Where Mei et al. (2001) developed a new scale of service quality in the hospitality industry, called "HOLSERV," with three dimensions: (1) employees, (2) tangibles, and (3) reliability. Brady \& Cronin (2001) proposed a third order factor model service which consisted of three primary dimensions (interaction quality, physical environment and outcome quality) and nine sub dimensions. Researchers such as Svensson, G (2004) presented a modified construct of chronological service quality and highlighted the importance of time, context, and performance threshold, in service-encounter chains. Shahin A. (2010) laid down a more comprehensive model of service quality consists of five additional components and eight more gaps as compared to the previous GAP model. The SERVQUAL five new components included in the developed model services were ideal standards; transformation of strategy and service industries.

It is clear from the previous measures that researchers adopt one of two conceptualizations in their research, the 
American perspective (focus on functional quality dimension, or the European perspective (consider two more components, technical quality and image). The American perspective of service quality is based primarily on Parasuraman et al.'s $(1985,1988)$. Where the European perspective found in lithenin and lethinen (1991), Gronroos models (1982).

\subsubsection{Health Care Service Quality Concept}

The interest in health care service quality is increasing. With increasing pressure to measure quality, patient based assessments of medical care are becoming increasingly important. Patients offer a unique perspective for evaluating the nontechnical aspects of medical care. In literature, there are various definitions of healthcare service quality. The Institute of Medicine defines healthcare quality as "the degree to which healthcare services for individuals and populations increase the likelihood of desired health outcomes and are consistent with current professional knowledge (U.S.National library of medicine,2017). According to Donabedian (1988), healthcare quality is "the application of medical science and technology in a manner that maximizes its benefit to health without correspondingly increasing the risk". Ovretveit \& Twonsend (1992) looked to healthcare service quality care as "the provision of care that exceeds patient expectations and achieves the highest possible clinical outcomes with the resources available".

Mosadeghrad (2011) defined Quality healthcare as "consistently delighting the patient by providing efficacious, effective and efficient healthcare services according to the latest clinical guidelines and standards, which meet the patient's needs and satisfies providers". For the purpose of this research healthcare service quality is defined as "healthcare services provided in Al-Bashir hospital whose characteristics and features meet or exceed patient's needs and expectations".

\subsubsection{Health Care Service Measures}

In the health care literature various measurement have been developed or adapted to measure health care service quality, such as : Evans and Lindsay (1999), Coddington and Moree (1987), Parasuraman et al. (1988), Cronin and Taylor (1992), Jenkinson C., et al. (2002), Dabholker et al (2000), Sower et al,(2001), Myer and collier (2001), Leebov et al. (2003), Kesuma ,I .A et al., (2013), Donabedian [2005), Diab,.(2012), Butler and McNamara (2015), Devi ,K.V,P.R.,(2016),Lee\& kim (2017) and Joint Commission on Accreditation of Health Care Organization (1996). Service quality measurements have been applied in different areas of health care to assess patients' perception regarding patient satisfaction (Bowers et al., 1994), physicians (Brown and Swartz, 1989), nurses (uzun, 2001, Özlü,Z and Uzun, O, 2015), hospitals (lim \& Tang, 2000) and healthcare services provided (Sadeghi1\& Hosseinian, 2014). The service quality in health care was based on two dimensions: the technical quality and functional quality applying Gronroos' perspective.

It is clear that service quality measurements in health care developed based on SERVIQUAL. For instance, Johnston (1995) increased SERVIQUAL scale to 18 dimensions, Camilleri and O' Callagran (1998) included dimensions such as: "professional and technical care, service personalization, price, environment, patient amenities, accessibility and caring. Lim and Tang (2000) have added "accessibility and affordability" "caring and outcomes" in their research, Tucker and Adams (2001) have added "caring and outcome". In this study, initial SERVIQUAL model will be applied to measure health care services at a major public hospital in Jordan.

\subsubsection{SERVIQUAL MODEL}

In the health care literature, various measurement items for healthcare service quality have been developed. Service quality measurement in health care developed in time based on the framework of SERVQUAL. Despite all limitations regarding SERVQUAL proved to be a successful background in health care. The service quality model "SERVQUAL"' ranks as the most important of service quality models and one of the widely used models to measure quality in service areas because of its comprehensiveness and practical applicability(lee and kim,2017). Other researchers such as: O'Conner et al., (2001), Pakdil and Harwood (2005), Qin and Prybutok (2009), found that SERVQUAL instruments suitable to analyze the perceptual gap in understanding patient expectation among health care stakeholders, a useful model to measure the differences between patients' preferences and their actual experiences and five dimensions of the service quality in SERVQUAL instrument are significant and reliable in a health care setting (Chakraborty and Majumdar, 2011).

It includes five service quality dimensions: Reliability, Assurance, Tangibles, Empathy and Responsiveness, and assessed by 22 items. It is based on the assumption that service quality is a function of differences (gaps) between customer expectations and perceptions along five quality dimensions: reliability, responsiveness, tangibles, assurance and empathy:-

- Reliability reflects the ability to perform the promised service dependably and accurately 
- Assurance include the knowledge and courtesy of employees and their ability to convey trust and confidence

- Tangibles include the appearance of physical facilities, equipment, personnel and communication materials

- Empathy is the provision of caring, individualized attention to customer

- Responsiveness: indicates the willingness to help customers and to provide prompt service

\subsubsection{Patient Satisfaction}

Hospitals have always been a place of care that provides the population with complete healthcare, both curative and preventive. In the hospitals, quality of care is measured with two metrics: patient outcomes and patient satisfaction. Satisfaction is a person's feelings of pleasure or disappointment resulting from comparing a product's or service's perceived performance (or outcome) in relation to his or her expectations. (Kotler, 2000). Patient satisfaction is defined as the appraisal, by an individual, of the extent to which the care provided has met that individual's expectations and preferences (Brennan 1995). It is the degree to which the individual regards the healthcare service, product or the manner in which it is delivered by the provider as useful, effective, or beneficial (Online Medical Dictionary, 2012). Patient satisfaction mostly appears to represent attitudes towards care or aspects of care (Jenkinson et al.. 2002).It is referred to patient satisfaction as patients' emotions, feelings and their perception of delivered healthcare services (Mohan \& Saikumar, 2011). The concept of patient satisfaction is multidimensional, and reflects patient perceptions and expectations compared to the actual care they receive (Edlund MJ,et al, 2003). Speight (2005) saw that the implicit in patient satisfaction definitions is the assumption that the patient attaches values to specific attributes of the treatment or service, and that these are unique to each individual's experience. It is found that patient satisfaction increases patient retention, willingness to recommend, improve the rate of patient compliance with physician advice and requests. It improves trust, loyalty and decreases the number of lawsuits. Service quality is often regarded as the antecedent of patient satisfaction ( Irfan (2012, Speight 2005, Zarei et al. (2012), Shan et al., (2016). For these reasons patient satisfaction survey is an effective tool that provides information and insight on patients' views of the services they receive. For the purpose of this research overall patient satisfaction was defined as "the extent to which outpatient is content with the healthcare services which they received from al-Bashir Hospital".

\subsection{Previous Studies}

Since 1985, many researchers have applied SERVQUAL to assess perceived service quality in the hospital sector in different countries.

Irfan et al (2012) found that public hospitals are not making any visible efforts to meet patient's needs and wants. the studied service quality construct does not have a significant impact on patient satisfaction except assurance.

Zarei et al. (2012) studied service quality in the private hospitals of Iran from the patients' perspective. Results indicated that tangible has the highest expectations and perceptions and the lowest expectation and empathy perception has the lowest expectations.

Punnakitikashem et al. (2012) measured service quality of the hospital implementing lean management. Study found that the service quality level of the hospital implementing lean is moderate. In addition, the largest positive gap between patients' perception and expectation is in term of tangibility.The largest negative gap is with respect to assurance.

Yousapronpaiboon \& Johnson (2013) studied Out-patient service quality perceptions in private Thai hospitals, results found that assurance was the dimension most strongly associated with overall PSQ, followed by empathy, responsiveness, tangibles and reliability.

Essiam (2013) examined the quality dimensions and patient satisfaction in a public university hospital in Ghana. Findings revealed gaps across all the SERVQUAL dimensions with SERVIQUAL dimensions. Patients' satisfaction was best explained by perceived responsiveness, followed by perceived empathy, perceived assurance, perceived tangibility, and perceived reliability.

Mosadeghrad (2014) conducted an exploratory in-depth individual and focus group interviews with 222 healthcare stakeholders including healthcare providers, managers, policy-makers, and payers to identify factors affecting the quality of healthcare services provided in Iranian healthcare organizations.. Results found that personal factors related to the provider and patient, factors pertaining to the health care organization, health care system and broader environment affected health care service quality.

Belaid et al (2015) studied the impact of health service quality and its impact on patient's satisfaction, case in a public hospital in Bechar. Results indicated that there was a relationship between overall service quality and 
patients' satisfaction with the services of specific hospital.

Özlü and Uzun ( 2015) found that there were differences in patient satisfaction with nursing care in surgery clinics in different hospitals in turkey related to educational background, profession, the hospital in which the patients stay and previous hospital experience .

Shan (2016) found that lack of trust was behind patient dissatisfaction with hospital inpatient care in Heilongjiang in China.

Devi and Muthuswamy (2016) investigated service quality perception in multispecialty hospitals in India. Result indicated that tangibility, reliability and responsiveness were the three most important dimensions of hospital service quality perceived by patients

Within the context of Arabic countries, Alasad and Muayyad (2003 found that patients in surgical wards had lowest levels of patients' satisfaction with nursing care at a major teaching hospital in Jordan. Demographic characteristics (Gender, educational level, and having other diseases) were significant predictors for patients' satisfaction with nursing care.

Zamil et al ((2012) investigated the impact of health service quality on patients' satisfaction over private and public hospitals in Jordan. The result indicated that there was an impact of health service quality on patient's satisfaction. Responsiveness dimension has the lowest mean out of other service quality diminutions in public and private sectors

Diab (2012) found that government hospitals in Jordan applied medical service dimensions of reliability, tangibility, empathy, and safety at high level from patient and staff perspective and there were no differences in the dimensions of quality attributed to any of the demographic variables.

Alghamdi, (2014) result indicated that Patient satisfaction was influenced by health service quality, with the empathy dimension as the greatest influence on patient satisfaction in government hospitals in Southern Saudi Arabia. Ajarmah et al. (2015), compared accredited and non-accredited hospitals in relation to patient's satisfaction in Jordan. Results show that accreditation improves patients' satisfaction.

Abdelgdir (2015) found that patients and reviewers are fully aware of levels of quality health services provided in government hospitals in Sudan \& there were no statistically significant differences in the levels of quality of health services in government hospitals depending on the demographic variables of the sample of gender, age, education, income, place of residence.

\section{Research Methodology}

The case study was conducted in outpatient clinics at Al-Bashir Hospital from August 2016 to January 2017 on 448 patients. The study was reviewed and approved by the hospital director. The criteria for sample selection were: an adult of 18 years or above and visiting Al-Bashir hospital seeking health services during the previous 6 months.

The researcher used two sources for data collection and they are: secondary sources by referring to text books, periodical journals, etc. and primary sources in which the researcher used the questionnaire technique to collect data required for the research. The study sampled out patients randomly selected from outpatient department at Al-Bashir hospital. Questionnaires were distributed to 500 outpatients, 460 questionnaires were received, and 12 questionnaires were excluded. The questionnaire was in three parts. Part A included personal information about the sample, such as information regarding, their education, gender, age, income and residency. Part B included information on the independent variable (reliability, responsiveness, tangibles, assurance \& empathy). Part $\mathrm{C}$ included questions regarding patient satisfaction. Sample answered questions on a five point Likert scale ranging from 1 (strongly disagree) to 5 (strongly agree). The research model was developed by the researcher employing SERVQUAL model which has been developed by Parasuraman et al. (1988) to measure healthcare quality perception. Dimensions of perceived service quality were measured using 22 items.

These dimensions along with their range of items include 'Tangibles' (4) items, 'Reliability' (5) items, 'Responsiveness' (4) items, 'Assurance' (4) items and 'Empathy' (5) items. Overall, customer satisfaction was measured using 6 items. An interval class was developed to analyze results of the study as follows: (1) Low; $1-2.33$, (2) medium; 2.34 to 3.66 , (3) High (3) 3.67 to 5.00 . The instrument was validated through a panel of referees; academic and professional experts with high professional backgrounds.

Regarding reliability of the questionnaire, a Cronbach Alpha for each dimension was computed to check internal consistency. As shown in Table 1, Cronbach Alpha in this study ranged from (0.894 0-0.951). It is obvious that all values of alpha are high which indicates that for each measure of variable, the items are highly correlated, and 
hence highly consistent.

Table 1. Reliability test (Cronbach's alpha for measures of variables)

\begin{tabular}{lll}
\hline Variable & No of Items & Cronbach's Alpha \\
\hline Service Quality Dimensions & & \\
Reliability & 4 & 0.951 \\
Responsiveness & 5 & 0.944 \\
Assurance & 4 & 0.907 \\
Tangible & 4 & 0.894 \\
Empathy & 5 & 0.943 \\
Total & 22 & 0.927 \\
Patient satisfaction & 6 & 0.944 \\
\hline
\end{tabular}

\section{Results Analysis}

\subsection{Characteristics of the Survey Respondent}

Respondents of this study have quite diverse characteristics. The personal data taken from the respondents including gender, age, education, income and residence. As seen in table (2), it seems that majority of the respondents who took part in this research was female gender (61.6\%), between ages 40- 50 years $(34.2 \%)$. Result showed that $(80.8 \%)$ of the respondents hold diploma or less. The question on the income showed that having moderate income $(71.7 \%)$ and $(89.5 . \%)$ of the respondent's residence were in the capital.

Table 2. Characteristics of the survey respondent

\begin{tabular}{llll}
\hline Variable & & Frequency & Percent \\
\hline Gender & Male & 172 & 38.4 \\
& Female & 276 & 61.6 \\
Age & Total & 448 & 100.0 \\
& $20-29$ & 106 & 23.7 \\
& $30-39$ & 119 & 26.6 \\
& $40-49$ & 153 & 34.2 \\
Education & $50 \&$ above & 70 & 15.6 \\
& Total & 448 & 100.0 \\
& Diploma or less & 362 & 80.8 \\
& Bachelor & 80 & 17.9 \\
Income & Post graduate & 6 & 1.3 \\
& Total & 448 & 100.0 \\
& Low & 105 & 23.4 \\
& Moderate & 321 & 71.7 \\
Residence & High & 22 & 4.9 \\
& Total & 448 & 100.0 \\
& Capital & 401 & 89.5 \\
& Governance & 47 & 10.5 \\
& Total & 448 & 100.0 \\
\hline
\end{tabular}

\subsection{Descriptive Results}

Data was analyzed using descriptive statistical methods (mean and standard deviation). An interval class was developed as follows: (1) Low; 1-2.33, (2) medium; 2.34 to 3.66, (3) High (3) 3.67 to 5.00.

Table 3 and 4 show the means and standard deviation values of (22) quality service variables used in this study representing five service quality constructs, and the 6 items of overall patient satisfaction.

4.2.1 Health Care Service Quality Dimensions Results (Independent Variable) 
According to table 3, respondents' have perceived healthcare service quality practices as medium category with mean (3.61) and standard deviation (1.11). The average value of the respondents' perception about the extent of healthcare service quality practices were ranging from (3.48 to 3.71), with standard deviation that ranges from ( 0.93 to 1.23 ). The results for assurance dimension indicated highest practice with mean (3.71) and standard deviation (0.93), followed by reliability dimension with mean (3.61) and standard deviation (1.09),tangibles dimension has the third rank after reliability dimension with mean (3.60) and standard deviation (1.23), responsiveness dimension has the fourth rank after tangibles dimension with mean (3.59) and Standard deviation (1.11), and empathy dimension indicated lowest rank with Mean ( 3.48) and Standard Deviation (1.18). Where dimension of overall patient satisfaction was in medium category with mean (3.06) and standard deviation $=$ (0.82).

- Assurance dimension: - it was measured by 4 items. The assessment focused on reflecting the patient perspective to what extent assurance dimension is implemented at Al-Bashir Hospital. . As shown in table (4) it is obvious that respondents' have perceived assurance practices as high practice category. Statistical analysis revealed that assurance dimension has the first rank and highest arithmetic means with mean (3.71) and S.D (0.93). Overall means of all assurance items obtained from the sample are above the average, Where the item (A.1.3) "Hospital's patients feel secure in using its services" has the highest mean which is (3.97), and the item (A.1.4)" At the hospital, the staff courteous and friendly to patients ", has a medium category with the lowest mean which is (3.33). This result was expected because public health sector in Jordan is characterized by highly trained and well experienced health professionals. High percentage of medical consultants, qualified nurses and technicians those professionals were exposed to intensive and expensive training programs inside and outside the country.

- Reliability dimension: - it was measured by 4 items. The assessment focused on reflecting the patient perspective to what extent reliability dimension is implemented at Al-Bashir Hospital. From table (4) it is obvious that respondents' have perceived reliability practices as medium category. Statistical analysis revealed that reliability dimension has the second rank after assurance dimension with mean (3.61) and standard deviation (1.09). Overall means of all reliability items obtained from the sample are above the average, Where the item (A.2.4) "The hospital submits documented and reports/services without error" has the highest mean which is (3.76) and the item (A.2.5) "The hospital provides services within time "has a medium category and the lowest mean which is (3.43). The study attributed the result to the shortages of staff and heavy work load that led to shortening in the awareness of patients' need which affected the ability to scheduling at a time convenient to them.

- Tangibles dimension: - It was measured by 4 items. The assessment focused on reflecting the patient perspective to what extent tangibles dimension is implemented at Al-Bashir Hospital. From table (4) it is obvious that respondents' have perceived tangibles practices as medium category. Statistical analysis revealed that tangibles dimension has the third rank after reliability dimension with mean (3.60) and standard deviation (1.23). Overall means of all tangibles items obtained from the sample are above the average, Where the item (A.3.1) "The medical equipment of the hospital is modern" has the highest mean which is (3.77), and the item (A.3.2)" Waiting facilities for attendants and patients in good status ", has the lowest mean which is (3.40) with medium category. The study attributed the result to the limited financial resources challenges which have negatively affected its investment in facilities.

- Responsiveness dimension: - it was measured by 5 items. The assessment focused on reflecting the patient perspective to what extent responsiveness dimension is implemented at Al-Bashir Hospital. From table (4) it is obvious that respondents' have perceived responsiveness practices as medium category. Statistical analysis revealed that responsiveness dimension has the fourth rank after tangibles dimension with mean (3.59) and Standard deviation (1.11). Overall means of all responsiveness items obtained from the sample are above the average, Where the item (A.4.3) "Doctors/staff efficiently respond to the patient's requests" has the highest mean which is (3.74) with high category and the item (A.4.4) "At the hospital there is a good feedback mechanism" has a medium category and the lowest mean which is (3.43). Also, the study attributed the result to the shortages of staff and heavy work load.

- Empathy dimension: - it was measured by 5 items. The assessment focused on reflecting the patient perspective to what extent empathy dimension is implemented at Al-Bashir Hospital. From table (4) it is obvious that respondents' have perceived empathy practices as medium category. Statistical analysis revealed that empathy dimension has the fifth rank with mean (3.48) and S.D (1.18). Overall means of all empathy items obtained from the sample are above the average, Where the item (A.5.4) "The hospital prioritizes the interests of the patients" "has the highest mean which is (3.67), and the item (A.5.2)" The hospital operates at times suitable 
to the patients ", has the lowest value which is (3.32). The study attributed the causes of medium level of perceived empathy practices at Al-Basheer hospital to the number of reviewer's pressure and long lines in outpatient clinics which affected the provision of caring and individualized attention to outpatients.

\subsubsection{Overall Patient Satisfaction (Dependent Variable)}

It was measured by 6 items. The assessment focused on a measuring the extent to which outpatient is content with the healthcare services which they received from al-Bashir Hospital.

As shown in table 4 statistical analysis revealed that respondents' have perceived over all patient satisfaction practices as medium category with mean (3.061) and S.D (0.827). Overall means of all patient satisfaction items obtained from the sample are above the average, Where the item (B.2) "Overall, I am satisfied with the treatment at the hospital" has the highest mean which is (3.22) with medium category and the item (B.1) "Overall, I am satisfied with the hospital's location "has a medium category and the lowest mean which is (2.86). The study attributed the causes of medium level of perceived overall patient satisfaction to the limited resources, heavy work load and low motivation to satisfy patients.

Table 3. Mean, Standard Deviation of Research Variables

\begin{tabular}{lcccl}
\hline Variable & Mean & S.D. & Rank & Importance \\
\hline Service Quality Dimensions & & & & \\
Assurance & 3.71 & 0.93 & 1 & High \\
Reliability & 3.61 & 1.09 & 2 & Medium \\
Tangibles & 3.60 & 1.23 & 3 & Medium \\
Responsiveness & 3.59 & 1.11 & 4 & Medium \\
Empathy & 3.48 & 1.18 & 5 & Medium \\
Total & 3.61 & 1.11 & & Medium \\
Patient Satisfaction & 3.06 & 0.82 & & Medium \\
\hline
\end{tabular}

Table 4. Descriptive Statistics of the Service Quality Constructs and overall patient satisfaction

\begin{tabular}{|c|c|c|c|c|c|}
\hline A. & Service Quality Variables & & Rank & Importance & \\
\hline & \multicolumn{5}{|l|}{ A.1.Assurance } \\
\hline & A. 1.1 The patients trust Doctor's expertise and skills & 3.72 & 0.997 & 3 & high \\
\hline & A. 1.2 The patients trust Nurses expertise and skills & 3.81 & 1.01 & 2 & high \\
\hline & A. 1.3 Hospital's patients feel secure in using its services & 3.97 & 0.84 & 1 & high \\
\hline & A. 1.4 At the hospital, the staff courteous and friendly to patients & 3.33 & .884 & 4 & medium \\
\hline & Total & 3.71 & 0.93 & & high \\
\hline & \multicolumn{5}{|l|}{ A.2. Responsiveness } \\
\hline & A.2.1 At the hospital, the staff meet promptly the patients' needs & 3.60 & 1.06 & 2 & medium \\
\hline & A.2.2 Patients are observed according to appointment & 3.57 & 1.11 & 3 & medium \\
\hline & A. 2.3 Doctors/staff efficiently respond to the patient's requests & 3.74 & 1.04 & 1 & high \\
\hline & A. 2.4 At the hospital there is a good feedback mechanism & 3.43 & 1.22 & 4 & medium \\
\hline & Total & 3.59 & 1.11 & & medium \\
\hline & \multicolumn{5}{|l|}{ A.3. Reliability } \\
\hline & $\begin{array}{l}\text { A. } 3.1 \text { The hospital performs the services and procedures correctly from the } \\
\text { first time }\end{array}$ & 3.60 & 1.06 & 3 & medium \\
\hline & $\begin{array}{l}\text { A. } 3.2 \text { The hospital shows special attention to the problems and queries of } \\
\text { patients }\end{array}$ & 3.55 & 1.07 & 4 & medium \\
\hline & A.3.3 The patient feels confident when receiving medical treatment. & 3.70 & 0.96 & 2 & high \\
\hline & A. 3.4 The hospital submits documented and reports/services without error & 3.76 & 1.16 & 1 & high \\
\hline & A.3.5 The hospital provides services within time & 3.43 & 1.22 & 5 & medium \\
\hline & Total & 3.61 & 1.09 & & medium \\
\hline \multicolumn{6}{|c|}{ A.4.Tangible } \\
\hline & A.4.1 The medical equipment of the hospital is modern & 3.77 & 1.01 & 1 & High \\
\hline & A. 4.2 Waiting facilities for attendants and patients in good status & 3.40 & 1.65 & 4 & medium \\
\hline
\end{tabular}




\begin{tabular}{|c|c|c|c|c|}
\hline A.4.3 Healthy environment at hospital & 3.67 & 1.15 & 2 & High \\
\hline A.4.4 The hospital toilets/bathrooms are clean & 3.57 & 1.11 & 3 & medium \\
\hline Total & 3.60 & 1.23 & & medium \\
\hline \multicolumn{5}{|l|}{ A.5 Empathy } \\
\hline A. 5.1 At the hospital, the team pay individual attention to each patient & 3.60 & 1.09 & 2 & medium \\
\hline A. 5.2 The hospital operates at times suitable to the patients & 3.32 & 1.23 & 5 & medium \\
\hline A. 5.3 The hospital takes into account the traditions prevailing in society & 3.43 & 1.22 & 4 & medium \\
\hline A. 5.4 The hospital prioritizes the interests of the patients & 3.67 & 1.17 & 1 & medium \\
\hline A.5.5 The medical staff response to patients' complaints & 3.40 & 1.19 & 3 & medium \\
\hline Total & 3.48 & 1.18 & & medium \\
\hline \multicolumn{5}{|l|}{ B. Overall patient satisfaction } \\
\hline B.1 Overall, I am satisfied with the hospital's location. & 2.86 & 0.83 & 6 & medium \\
\hline B.2 Overall, I am satisfied with the treatment at the hospital & 3.22 & .680 & 1 & medium \\
\hline B.3 Overall, I am satisfied with medical care at the hospital & 3.20 & .750 & 2 & medium \\
\hline B.4 Overall, I am satisfied with the nursing care at the hospital & 3.07 & .990 & 3 & medium \\
\hline B.5 Overall, I am satisfied with the hospital management & 3.01 & .840 & 4 & medium \\
\hline B.6 I would recommend the hospital to others & 3.00 & .840 & 5 & medium \\
\hline Total & 3.06 & 0.82 & & medium \\
\hline
\end{tabular}

Therefore, from the above results it can be concluded that patients perceived the hospital workers acquire knowledge, and skills as well as their ability to inspire trust and confidence. Patients are assured that they are getting the best healthcare services from best doctors and nurses. On the other hand, the lowest average, although it is in medium category, provides insights some of respondents experienced that individual attention to each patients and responses to patients complains are not meeting the patient expectations which require further efforts to be made in this issue. Regarding overall patient satisfaction respondents' have perceived over all patient satisfaction practices as medium category, it can be concluded that patients were moderately satisfied with the medical, nursing and management services provided in the hospital However, moderate results should be elevated in the future. Possible reasons that Al-Bashir hospital is facing a lot of challenges resulted from the limited resources heavy work load and brain drainage that may lead to shortening in the awareness of patients need.

In general, results indicated that outpatients in Al-Bashir hospital receive acceptable level of healthcare service quality from their perspective and moderately satisfied from overall hospital services.

\subsection{Analytical Results}

Data was analyzed through following analytical statistical methods: - multiple regression, step wise multiple regression, one-way ANOVA and Pearson correlation coefficient.

The First Hypothesis (H01): There is no statistically significant impact at $(\alpha \leq 0.05)$ of healthcare service quality (reliability, responsiveness, tangibles, assurance, empathy) on overall patient satisfaction at Al-Bashir Hospital

As shown in table (5) The ANOVA table shows that the F-statistic was (15.588) and a significance level of (0.000). Therefore, the null hypothesis is rejected and the alternative hypothesis is accepted, proving that there is an impact of healthcare service quality (reliability, responsiveness, tangibles, assurance, empathy) on overall patient satisfaction.

Based on the multiple regression models, three predictor variables were found to be significant in explaining patient satisfaction. The reliability dimension had the greatest influence on patient satisfaction, $(\beta 1=0.333)$, followed by empathy $(\beta 1=0.210)$, and assurance $(\beta 1=0.152)$. The R-squared of $(.015)$ means that the $15.0 \%$ of the variation in patient satisfaction was explained by three variables. The above results showed that improving reliability, assurance and empathy will have a positive impact on over all patient satisfaction.

Table 5. Regression Analysis of healthcare service quality (reliability, responsiveness, tangibles, assurance, empathy) on overall patient satisfaction 


\begin{tabular}{|c|c|c|c|c|}
\hline Model & $\mathrm{R}$ & R Square & Adjusted R Square & $\begin{array}{l}\text { Std. Error of the } \\
\text { Estimate }\end{array}$ \\
\hline 1 & $.387^{\mathrm{a}}$ & .150 & .140 & .44295 \\
\hline
\end{tabular}

a. Predictors: (Constant), Empathy, Responsiveness, Tangible, Assurance, Reliability

\begin{tabular}{|c|c|c|c|c|c|c|}
\hline \multicolumn{5}{|c|}{ ANOVA } & \multirow[b]{2}{*}{$\mathrm{F}$} & \multirow[b]{2}{*}{ Sig. } \\
\hline Model & & Sum of Squares & df & Mean Square & & \\
\hline \multirow[t]{3}{*}{1} & Regression & 15.292 & 5 & 3.058 & 15.588 & $.000^{\mathrm{a}}$ \\
\hline & Residual & 86.723 & 442 & .196 & & \\
\hline & Total & 102.016 & 447 & & & \\
\hline
\end{tabular}

Coefficients'

\begin{tabular}{|c|c|c|c|c|c|c|}
\hline \multirow{2}{*}{\multicolumn{2}{|c|}{ Model }} & \multicolumn{2}{|c|}{ Unstandardized Coefficients } & \multicolumn{3}{|c|}{$\begin{array}{l}\text { Standardized } \\
\text { Coefficients }\end{array}$} \\
\hline & & $\mathrm{B}$ & Std. Error & Beta & $\mathrm{t}$ & Sig. \\
\hline \multirow[t]{6}{*}{1} & (Constant) & 2.329 & .291 & & 8.014 & .000 \\
\hline & Reliability & .336 & .050 & .330 & 6.761 & .000 \\
\hline & Responsiveness & $-.058-$ & .042 & $-.070-$ & $-1.385-$ & .167 \\
\hline & Assurance & .149 & .048 & .152 & 3.129 & .002 \\
\hline & Tangible & $-.047-$ & .042 & $-.054-$ & $-1.139-$ & .255 \\
\hline & Empathy & .096 & .021 & .210 & 4.658 & .000 \\
\hline
\end{tabular}

(H02): There are no significant differences at $(\alpha \leq 0.05)$ in patient perceptions of health service quality dimensions due to demographic variables (gender, age, education, income and residence). As shown in table 6 one-way Variance table shows that significance level of all variables are above (0.05). Therefore, the null hypothesis is accepted and the alternative hypothesis is rejected, proving that there are no are no significant differences at $(\alpha \leq 0.05)$ in patient perceptions of health service quality dimensions due to demographic variables (gender, age, education, income and residence).

Table 6. One way analysis of variance (ANOVA) results

\begin{tabular}{|c|c|c|c|c|c|c|}
\hline & & Sum of Squares & $\mathrm{df}$ & Mean Square & $\mathrm{F}$ & Sig. \\
\hline \multirow[t]{4}{*}{ Gender } & Between & .217 & 1 & .217 & 2.383 & .123 \\
\hline & Groups & & & & & \\
\hline & Within Groups & 40.520 & 446 & .091 & & \\
\hline & Total & 40.736 & 447 & & & \\
\hline \multirow[t]{4}{*}{ Age } & Between & .328 & 3 & .109 & 1.202 & .308 \\
\hline & Groups & & & & & \\
\hline & Within Groups & 40.408 & 444 & .091 & & \\
\hline & Total & 40.736 & 447 & & & \\
\hline \multirow[t]{4}{*}{ Education } & Between & .692 & 2 & .346 & 3.844 & .062 \\
\hline & Groups & & & & & \\
\hline & Within Groups & 40.044 & 445 & .090 & & \\
\hline & Total & 40.736 & 447 & & & \\
\hline \multirow[t]{4}{*}{ Income } & Between & .063 & 2 & .032 & .346 & .708 \\
\hline & Groups & & & & & \\
\hline & Within Groups & 40.673 & 445 & .091 & & \\
\hline & Total & 40.736 & 447 & & & \\
\hline \multirow[t]{2}{*}{ Residence } & Between & .006 & 1 & .006 & .062 & .804 \\
\hline & Groups & & & & & \\
\hline
\end{tabular}




\begin{tabular}{cccc}
\hline Within Groups & 40.730 & 446 & .091 \\
Total & 40.736 & 447 & \\
\hline
\end{tabular}

\section{Conclusion}

The aim of this study was to test the impact of healthcare service quality (reliability, responsiveness, tangibles, assurance, empathy) on overall patient satisfaction at Al-Bashir hospital.

Major conclusions of this study are as follow:

1. The study proved that there is an impact of healthcare service quality on overall patient satisfaction. Correlations and multiple regression techniques proved that there is statistically significant impact of healthcare service quality on overall patient satisfaction. The reliability dimension had the greatest influence on patient satisfaction, followed by empathy and assurance, only $15.0 \%$ of the variation in patient satisfaction was explained by three variables.

2. The statistical analysis revealed that there were no differences in patient perceptions of health service quality dimensions attributed to any of the demographic variables (gender, age, education, income and residence).

3. Results show that perceived healthcare service quality practices as medium category. It was noted that assurance dimension has the highest mean and first category, followed by responsiveness, reliability, tangibles and empathy dimension has the lowest mean and category out of other service quality dimensions.

4. Results show that perceived overall patient satisfaction was in medium category. Patients were moderately satisfied with the medical, nursing and management services provided in the hospital.

5. It was noted that majority of the respondents who took part in this research was female gender $(61.6 \%)$, between ages $40-50$ years (34.2\%). Result showed that (80.8\%) of the respondents hold diploma or less, having moderate income and majority residence were in the capital.

The above finding is consistent with previous studies, such as: Diab, (2012), Irfan et al (2012) Zamil et al ((2012), Zarei et al. (2012) Yousapronpaiboon \& Johnson (2013), Mosadeghrad (2014), Abdelgadir (2015) and Belaid et al (2015).

\section{Recommendations}

The researcher suggests that a moderate level of both perceived healthcare service quality practices and overall patient satisfaction at Al-Basher hospital should be improved. The following are the main suggestions:

A. Hospital administration is recommended to continue their commitment to provide medical services to patients in a timely manner. Furthermore, healthcare personnel must do their utmost to provide the patients with person-centred care.

B. Hospital administration is recommended to develop an advanced appointment system to solve the problems of overcrowded clinics and long working hours.

C. Hospital administration is recommended to give more attention to patients' problems, better response to patients' complaints, and pay special attention to their care.

D. Hospital administration is recommended to provide attendants and patients with appropriate waiting facilities and restrooms.

E. Hospital administration is recommended to develop the employees' communication skills in respect of dealing with patient and the level of response to their needs, giving them empathy and safety.

F. Hospital administration is recommended to regularly assess patient perceptions and satisfactions through surveys, which could then be used to improve the quality of health care and overall patient satisfaction.

G. Hospital administration is recommended to provide employees with incentives and training courses which will have a positive effect on their job satisfaction and retention.

H. The tool used for measuring perceived healthcare quality and patient satisfaction is reliable and valid. The researcher suggests that Al-Bashir hospital can adapt this tool to enhance its quality improvement efforts.

\section{Limitations and Suggestions for Future Research}

The contribution of this research should be viewed in the light of some limitations. First, this study was limited to Al-Bashir hospital as a case study, which limited the generalization of the findings. Second, this research conceptualized service quality from the patient perspective. The researcher suggests other researches perceive 
healthcare quality from the perspective of other stakeholders.

\section{Acknowledgments}

The author is grateful to Amman Arab University for funding this study. Thanks also extended to Al-Bashir hospital director for the approval and facilitating the task of performing this survey. I would like to also thank all the survey respondents for their participation in the survey.

\section{References}

Aagja, J. P., \& Garg, R. (2010). Measuring perceived service quality for public hospitals in the Indian context. International Journal of Pharmaceutical and Healthcare Marketing, 4(1), 60-83.

Abdelgadir, M. (2015). Measuring the Quality of Health Services in government hospitals in Sudan, from the Point of view of patients and reviewers. (A field Study on the Major Teaching Hospitals in Khartoum State). Jordan Journal of Business and Administration, 11(4),899-920. Retrieved from http://journals.ju.edu.jo/old/index.php/JJBA/article/view/9036/4720

Abu-Kharmeh, S. (2012). Evaluating the Quality of Health Care Services in the Hashemite Kingdom of Jordan. International Journal of Business and Management, 7(4), 195-205. Retrieved from www.ccsenet.org/journal/index.php/ijbm/article/download/12638/10229

Agency for healthcare research and quality. (2012). Understanding Quality Measurement. Retrieved from https://www.ahrq.gov/professionals/quality-patient-safety/quality-resources/tools/chtoolbx/understand/inde x.html

Ajarmah, B., \& Balqees, S., \& Hashem, T. (2015). Patient Satisfaction evaluation on hospitals: Comparison study between accredited and non-accredited hospitals in Jordan. European Scientific Journal, 11(32), 298-314. Retrieved from https://www.researchgate.net/publication/285234140

Ajlouni, M. (2010). Human resources for health country profile. WHO publication. Retrieved from http://apps.who.int/medicinedocs/documents/s17239e/s17239e.pdf

Alasad, J. A., \& Muayyad, M. A. (2003). Patients' satisfaction with nursing care in Jordan, International Journal of Health Care Quality Assurance 16(6), 279-28. Retrieved from https://www.researchgate.net/publication/238156688_Patients\%27_satisfaction_with_nursing_care_in_Jord an

ALfanek, F. (2017). Services bloom in Jordan's economy. Jordan times newspaper. Retrieved from http://www.jordantimes.com/opinion/fahed-fanek/services-bloom-jordan $\% \mathrm{E} 2 \% 80 \% 99$ s-economy

Alghamdi, F. S. (2014). The impact of service quality perception on patient satisfaction in government hospitals in southern Saudi Arabia. Saudi Medical Journal, 35(10), 1271-1273. Retrieved from https://www.ncbi.nlm.nih.gov/pmc/articles/PMC4362118/

Aliman, N., \& Mohamad, W. (2013). Perceptions of Service Quality and Behavioral Intentions: A Mediation Effect of Patient Satisfaction in the Private Health Care in Malaysia. International Journal of Marketing Studies, 5(4), 15-29. http://www.ccsenet.org/journal/index.php/ijms/article/viewFile/25449/16877

Belaid, H., Bouchenafa, A., Barich, A., \& Maazouzi, B. K. (2015). The Quality of Health Services in BECHAR Public Hospital Institution. International Journal of Social Sciences, IV(2), 1-14.

Brady, M. K., \& Cronin, Jr. (2001). Some New Thoughts on Conceptualizing Perceived Service Quality: A Hierarchical Approach. Journal of Marketing. 65, 34-49. Retrieved from https://pdfs.semanticscholar.org/d2b8/3722700b1d99fd13b1cb95586b1bfd82d8f3.pdf +

Brennan, P. F. (1995). Patient satisfaction and Normative Decision Theory. Journal of the American Medical Informatics Association, 2(4), 250-259. https://www.ncbi.nlm.nih.gov/pmc/articles/PMC116263/pdf/0020250.pdf

Brennan, P. F., \& Strombom, I. (1998). Improving Health Care by Understanding Patient Preferences. The Role of Computer technology. Journal of the American Medical Informatics Association, 5(3), 257-262. https://www.ncbi.nlm.nih.gov/pmc/articles/PMC61299/

Brown, S. W., \& Swartz, T. A. (1989). A Gap Analysis of Professional Service Quality. Journal of Marketing, 53, 92-98. Retrieved from https://www.researchgate.net/publication/244415476_A_Gap_Analysis_of_Professional_Service_Quality

Chakraborty, R., \& Majumdar, A. (2011). Measuring consumer satisfaction in health care sector: The 
applicability of SERVQUAL. International Refereed Research Journal, 2(4), 149-160. Retrieved from http://www.researchersworld.com/vol2/issue4/Paper_17.pdf

Cronin J, Jr., \&Taylor, S. (1992). Measuring Service Quality: A Reexamination and Extension. Journal of Marketing, 55-58. Retrieved from

http://content.ebscohost.com/ContentServer.asp?T=P\&P=AN\&K=9211164404\&S=R\&D=bth\&EbscoConte $\mathrm{nt}=\mathrm{dGJyMNHr} 7 \mathrm{ESeprc4yOvqOLCmr0 \% 2BeprdSr6y4TLWWxWXS \& ContentCustomer=dGJyMPGotFGw}$ qbVJuePfgeyx44Dt6fIA

Cronin, J. Jr., \& Taylor, S. (1994). SERVPERF Versus SERVQUAL: Reconciling Performance-Based and Perceptions-Minus-Expectations Measurement of Service Quality. Journal of Marketing, 58, 125-131. Retrieved from http://content.ebscohost.com/ContentServer.asp?T=P\&P=AN\&K=9406201514\&S=R\&D=bth\&EbscoConte nt=dGJyMNHr7ESeprc4yOvqOLCmr0\%2BeprdSr6i4Sq\%2BWxWXS\&ContentCustomer=dGJyMPGotFG wqbVJuePfgeyx44Dt6fIA

Dabholkar, P. A., Thorpe, D. I., \& Rentz, J. O. (1996). A measure of service quality for retail stores:scale development and validation. Journal of the Academy of Marketing Science, 3-16. Retrieved from http://content.ebscohost.com/ContentServer.asp? $\mathrm{T}=\mathrm{P} \& \mathrm{P}=\mathrm{AN} \& \mathrm{~K}=9603062854 \& \mathrm{~S}=\mathrm{R} \& \mathrm{D}=$ bth \&EbscoConte $\mathrm{nt}=\mathrm{dGJyMNHr7ESeprc4yOvqOLCmr0 \% 2BeqK5Sr664SrWWxWXS \& ContentCustomer=dGJyMPGotFGw}$ qbVJuePfgeyx44Dt6fIA

Devi, K. V., \& Muthuswamy, P. R. (2016). A Study on service quality GAP in multi-specialty hospitals, Management, Indian Journal of applied research, 6(12), 616-617. Retrieved from https://www.worldwidejournals.com/indian-journal-of-applied-research-(IJAR)/file.php?val=December_20 16_1480576100_205.pdf

Diab, S. (2012). Measuring Quality Dimensions of Government Hospitals Medical Services in Jordan: A Staff and Patients Perspective. IUG Journal of economics and Business Studies, (20), 69-104. Retrieved from http://www.iugaza.edu.ps/ar/periodical/

Donabedian, A. (1988). The Quality of Care How Can It Be Assessed? Retrieved from http://www.nursingworld.org/DocumentVault/Care-Coordination-Panel-Docs/background-docs/Jun-4-Mtgdocs/The-Quality-of-CareHowCanItBeAssessed-Donabedian1988.pdf

Edlund, M. J., Young, A. S., Kung, F. Y., Sherbourne, C. D., \& Wells, K. B. (2003). Does Satisfaction Reflect the technical quality of mental health care. Health Services Research, 38(2), 631-645. Retrieved from https://www.ncbi.nlm.nih.gov/pmc/articles/PMC1360907/pdf/hesr_137.pdf

Essiam, J. O. (2013). Service Quality and Patients Satisfaction with Healthcare Delivery empirical evidence from patients of the outpatient department of a public university hospital in Ghana. European Journal of Business and Management, 5(28), 52-59. Retrieved from http://journals.iugaza.edu.ps/index.php/IUGJEB/article/view/422/384

Gronroos C. (1982), Strategic Management \& Marketing in Service Sector. Swedish school of economics and business administration. Helsingfors, Finland . (published in 1983 in the US by Marketing Science Institute and in the UK by student litteratur/Chartwell -Bratt)

Gronroos, C. (1994). From Scientific Management to Service Management A Management Perspective for the Age of Service Competition. International Journal of Service Industry Management, 5(1), 5-20. Retrieved from https://www.iei.liu.se/fek/frist/722g60/gruppernas_artiklar_och_presentationer/1.163364/http__www.emer aldinsight.com.lt.ltag.bibl.liu.se_Insight_ViewContentServlet_contentTypeArticleFilename_published_eme raldfulltextarticle_pdf_0850050101.pdf

Gronros, C. (1984). Strategic management and marketing in the service sector-A service quality model and its marketing implications. European Journal of Marketing, 18(4), 36-44. Retrieved from https://www.researchgate.net/publication/233522386_A_Service_Quality_Model_and_Its_MarketingImplic ations

Irfan, M., Ijaz, A., \& Farooq, M. M. (2012). Patient Satisfaction and Service Quality of Public Hospitals in Pakistan: An Empirical Assessment. Middle-East Journal of Scientific Research, 12(6), 870-877. Retrieved from http://docplayer.net/23869065-Patient-satisfaction-and-service-quality-of-public-hospitals-in-pakistan-an-e 
mpirical-assessment.html

Jenkinson, C. A., Coulter, A., Bruster, S., Richards, N., \& Chandolaet, T. (2002). Patients' experiences and satisfaction with health care: results of a questionnaire study of specific aspects of care. Qual Saf Health Care, 11, 335-339. http://qualitysafety.bmj.com/content/qhe/11/4/335.full.pdf

Johnston, R. (1995). The determinants of service quality: satisfiers and dissatisfies. International Journal of Service Industry Management, 6(5), 53-571.

Joint Commission on Accreditation of healthcare organizations. (2011). Accreditation manual for hospitals. Retrieved from http://www.jointcommission.org/assets/1/6/accreditation_guide_hospitals_2011.pdf

Kang, G. D. (2006). The hierarchical structure of service quality: integration of technical and functional quality. Managing Service Quality, 16(1), 37-50. Retrieved from http://www.ida.liu.se/ steho87/und/htdd01/1080160104.pdf

Kang, G. D., \& James, J. (2004). Managing Service Quality, 14(4), 266-277. Retrieved from http://www.ida.liu.se/ steho87/und/htdd01/1080140401.pdf

Kesuma, I. A. W., Djumilah, Hadiwidjojo, N L P W., \& Rohman, F., (2013). Service Quality Influence on Patient Loyalty: Customer Relationship Management as Mediation Variable (Study on Private Hospital Industry in Denpasar). International Journal of Business and Commerce, 2(12), 1-14 Retrieved from http://www.ijbcnet.com/2-12/IJBC-13-21109.pdf

Kotler, P. (2000). Marketing Management (10th ed.). New Jersey, Prentice-Hall.

Kucukarslan, S., \& Nadkarni, A. (2008). Evaluating medication-related services in a hospital setting using the disconfirmation of expectations model of satisfaction, Research in Social and Administrative Pharmacy, 4(1), 12-22. http://www.rsap.org/article/S1551-7411(07)00002-2/pdf.

Lee \& Kim. (2017). Assessing healthcare service quality: a comparative study of patient treatmenttypes. International Journal of Quality Innovation, 3(1), 1-15. Retrieved from https://jqualityinnovation.springeropen.com/track/pdf/10.1186/s40887-016-0010-5?site=jqualityinnovation. springeropen.com

Lehtinen, U., \& Lehtinen, J. (1991), Two Approaches to Service Quality Dimensions. The Service industries Journal. 2(3), 287-303. Retrieved from http://web.a.ebscohost.com/ehost/pdfviewer/pdfviewer?vid=44\&sid=3cd17c7f-4d27-4ea9-9b1f-ebf59c5b3a ce $\% 40$ sessionmgr 4007

Lim, P. C., \& Tang, N. K. H. (2000). A study of patients' expectations and satisfaction in Singapore hospitals. International Journal Health Care Quality Assurance, 13, 290-299.

Mei, A.W. O., Dean, M. A., \& Christopher, J. W. (1999). Analyzing service quality in the hospitality industry. Managing Service Quality, 9(2), 136-143. Retrieved from https://www.researchgate.net/profile/Alison_Dean/publication/235262515_Analysing_service_quality_in_t he_hospitality_industry/links/56a586cb08aeef24c58be0bd/Analysing-service-quality-in-the-hospitality-ind ustry.pdf

Mels, G., Boshoff, C., \& Nel, D. (1997). The Dimensions of Service Quality: The Original European Perspective Revisited.The Service Industries Journal, 17(1), 173-189. Retrieved from http://web.a.ebscohost.com/ehost/pdfviewer/pdfviewer?vid=4\&sid=5786eaeb-3823-493b-b8c4-7adabe288d $43 \% 40$ sessionmgr 4010

Meyer, S. M., \& Collier, D. A. (2001). An empirical test of the causal relationships in the Baldrige Health Care Pilot Criteria. Journal of Operations Management, 19, 403-425. Retrieved from https://pdfs.semanticscholar.org/5943/5143757952b5aad56a03985b0b475b9f970c.pdf

Mohan, R., \& Saikumar, K. (2011). A study on the satisfaction of patients with reference to hospital services. ZENITH International Journal of Business Economics \& Management Research, 1(3), 15-25. Retrieved from http://zenithresearch.org.in/images/stories/pdf/2011/Dec/ZIBEMR/2_ZIBEMR_VOL1_ISSUE3.pdf

Mosadeghrad, A. M. (2011). Healthcare service quality: towards a broad definition. International Journal of Health Care Quality Assurance, 26(3), 203-219.

Mosadeghrad, A. M. (2014). Factors influencing healthcare service quality. International Journal of Health Policy and Management, 3(2), 77-89. Retrieved from http://www.ijhpm.com/article_2864_2639694b52ee2d50badb65bd92c90d7d.pdf 
National Strategy for Health Sector in Jordan. (2015-2019). Higher Health Council. Retrieved from http://www.hhc.gov.jo/uploadedimages/The\%20National\%20Strategy\%20for\%20Health\%20Sector\%20in\% 20Jordan\%202015-2019.pdf

Oliver, R. L. (1980). A Cognitive Model of the Antecedents and Consequences of Satisfaction Decisions. Journal of Marketing Research, 17, 460-469. Retrieved from http://web.a.ebscohost.com/ehost/pdfviewer/pdfviewer?vid=7\&sid=770810b3-3640-4b92-a8dc-5701892f75 $55 \% 40$ sessionmgr 4009

Ovretveit, J., \& Townsend, C. (1992). Health Service Quality: An Introduction to Quality Methods for Health Services, Blackwell scientific publications.

Özlü, Z., \& Uzun, O. (2015). Evaluation of Satisfaction with Nursing Care of Patients Hospitalized in Surgical Clinics of Different Hospitals. International Journal of Caring Sciences. Retrieved from http://www.internationaljournalofcaringsciences.org/docs/3-Karaman-\%20Original.pdf

Parasuraman, A., Zeithaml, V. A., \& Berry, L. L. (1985). A conceptual model of service quality and its implication, Journal of Marketing, 49, 41-50. Retrieved from https://edisciplinas.usp.br/pluginfile.php/2491773/mod_resource/content $/ 1 /$ Conceptual $\% 20$ Model $\% 20$ of $\% 2$ 0Service\%20Quality\%20and\%20Its\%20Implications\%20for\%20Future\%20Research.pdf.

Parasuraman, A., Zeithaml, V. A., \& Berry, L. L. (1988). SERVQUAL: a multi-item scale for measuring consumer perceptions of the service quality, Journal of Retailing, 64(1), 12-40. Retrieved from https://www.researchgate.net/profile/Valarie_Zeithaml/publication/225083802_SERVQUAL_A_multiple-_I tem_Scale_for_measuring_consumer_perceptions_of_service_quality/links/5429a4540cf27e $39 \mathrm{fa} 8 \mathrm{e} 6531 / \overline{\mathrm{SE}}$ RVQUAL-A-multiple-Item-Scale-for-measuring-consumer-perceptions-of-service-quality.pdf

Parasuraman, A., Zeithaml, V. A., \& Berry, L. L. (1991).Refinement and reassessment of the SERVQUAL scale. Journal of Retailing, 67(4), 420-450. Retrieved from http://web.a.ebscohost.com/ehost/pdfviewer/pdfviewer?vid=5\&sid=3cd17c7f-4d27-4ea9-9b1f-ebf59c5b3ac e\%40sessionmgr4007

Parasuraman, A., Zeithaml, V. A., \& Berry, L. L. (1993). Research note: more on improving service quality measurement. Journal of Retailing, 69(1), 140-147. Retrieved from http://web.a.ebscohost.com/ehost/pdfviewer/pdfviewer?vid=7\&sid=3cd17c7f-4d27-4ea9-9b1f-ebf59c5b3ac e\%40sessionmgr4007

Pelz, L. (1982). Toward a Theory of Patient Satisfaction. Social Science \& Medicine, 16, 577-582. Retrieved from https://www.researchgate.net/publication/16098043_Toward_a_Theory_of_Patient_Satisfaction

Punnakitikashem, P., Buavaraporn, N., Maluesri1, P., \& Leelartapin, K. (2012). Health Care Service Quality: Case Example of a Hospital with Lean Implementation. POMS 23rd Annual Conference, Chicago, Illinois, U.S.A

Ramanujam, P. G. (2011). Service Quality in Health Care organizations: A Study of Corporate Hospitals in Hyderabad. Journal of Health Management, 177-202. http://journals.sagepub.com/doi/pdf/10.1177/097206341101300204

Ramez, W. S. (2012). Patients' Perception of Health Care Quality, Satisfaction and Behavioral Intention: An Empirical Study in Bahrain, International Journal of Business and Social Science, 3(18), 131-141. Retrieved from https://pdfs.semanticscholar.org/cfla/d2f4a5d71421f754dfaee7c040acead46f61.pdf

Rocha, R. M., Veiga, D. F., Oliveira, P. R., Song, E, H., \& Ferreira, L. M. (2013). Health service quality scale: Brazilian Portuguese translation, reliability and validity. BMC Health Services Research, 13(24), 1-5. Retrieved from http://web.b.ebscohost.com/ehost/pdfviewer/pdfviewer?vid=4\&sid=ad06a358-d49c-41c3-b275-28bbe29d1 $1 \mathrm{c} 7 \% 40$ sessionmgr 104

Sadeghi, P., \& Hosseinian, T. (2014). Patient's satisfaction with healthcare services provided in Iran. International Research Journal of Applied and Basic Sciences, 8(12), 2339-2342. Retrieved from http://www.irjabs.com/files_site/paperlist/r_2465_150111154215.pdf

Seth, N., Deshmukh, S., \& Vrat, P. (2005). Service quality models: a review. International Journal of Quality \& Reliability Management, 22(9), 913-949.

Shahin, A. (2010). Developing the Models of Service Quality Gaps: A Critical Discussion. Business 
Management and Strategy, 1(1), 1-11. Retrieved from http://macrothink.org/journal/index.php/bms/article/viewFile/395/342

Shan, L., Li, Y., Ding, D., Wu, Q., Liu, C., \& Jiao, M., et al. (2016). Patient Satisfaction with Hospital Inpatient Care: Effects of Trust. Medical Insurance and Perceived Quality of Care, 1-18. Retrieved from http://journals.plos.org/plosone/article/file?id=10.1371/journal.pone.0164366\&type=printable

Smith, S. (1998). How to create a plan to deliver great customer service. In Zemke, R. \& Woods, J. A. (Eds.). Best Practices in Customer Service. New York, NY.

Speight, J. (2005). Assessing Patient Satisfaction: Concepts, Applications and Measurement. Value in health, 8(1), S6-S8. Retrieved from http://onlinelibrary.wiley.com/doi/10.1111/j.1524-4733.2005.00071.x/epdf

Svensson, G. (2004). A customized construct of sequential service quality in service encounter chains: Time, context, and performance threshold. Managing Service Quality, 14(6), 468-475. Retrieved from http://www.ida.liu.se/ steho87/und/htdd01/1080140603.pdf

Teas, R. K. (1993). Expectations, Performance Evaluation and Consumers' perception of Quality .Internaational Journal of Service Industry Management, 4(3), 30-49. Retrieved from http://content.ebscohost.com/ContentServer.asp? $\mathrm{T}=\mathrm{P} \& \mathrm{P}=\mathrm{AN} \& \mathrm{~K}=9402090910 \& \mathrm{~S}=\mathrm{R} \& \mathrm{D}=$ ufh \&EbscoConte $\mathrm{nt}=\mathrm{dGJyMNHr7ESeprc4yOvqOLCmr0 \% 2BeqK5Srq24S7WWxWXS \& ContentCustomer=dGJyMPGotFG}$ wqbVJuePfgeyx44Dt6fIA

Tucker, J., \& Adams, S. H. (2001). Incorporating patients' assessments of satisfaction and quality: An integrative model of patients' evaluations of their care: Managing Service Quality. An International Journal, 11(4), 272-287. https://doi.org/10.1108/EUM0000000005611

U.S.National library of medicine. (2017). Retrieved from https://www.nlm.nih.gov/hsrinfo/quality.html

Uzun, Ö. (2001). Patient satisfaction with nursing care at a university hospital in Turkey. Journal of Nursing Care Quality, 16(1), 24-33.

Yarimoglu1, E. K. (2014). A Review on Dimensions of Service Quality Models. Journal of Marketing Management, 2(2), 79-93. Retrieved from http://jmm-net.com/journals/jmm/Vol_2_No_2_June_2014/5.pdf

Yousapronpaiboon, K., \& Johnson, W. (2013). Out-patient Service Quality Perceptions in Private Thai Hospitals. International Journal of Business and Social Science, 4(2), 57-66. http://ijbssnet.com/journals/Vol_4_No_2_February_2013/7.pdf

Zamil, A., Areiqat, A., \& Tailakh, N. (2012). The Impact of Health Service Quality on Patients' Satisfaction over Private and Public Hospitals in Jordan: A Comparative Study. International Journal of Business and Social Science, 4(1), 123-137. Retrieved from http://www.ccsenet.org/journal/index.php/ijms/article/view/13152

Zarei, A., Arab, M., Froushani, A., Rashidian, A., \& Tabatabaei, S. M. G. (2012). Service quality of private hospitals: The Iranian Patients' perspective. BMC Health Services Research, 1-7. Retrieved from $\mathrm{http} / / / \mathrm{bmchealthservres.biomedcentral.com/track/pdf/10.1186/1472-6963-12-31?site=bmchealthservres.bio}$ medcentral.com

Zeithaml, V. A., Bitner, M. J., \& Gremler, D. D. (2006). Services Marketing - Integrating Customer Focus across the Firm (4th ed.). McGraw-Hill/Irwin, New York.

Zethamel, V. (1988). Consumer perception of price, quality and value; mean end model and synthesis of evidence. Journal of Marketing, (52), 2-22. Retrieved from https://hec.unil.ch/docs/files/123/997/zeithaml88-1.pdf

\section{Copyrights}

Copyright for this article is retained by the author(s), with first publication rights granted to the journal.

This is an open-access article distributed under the terms and conditions of the Creative Commons Attribution license (http://creativecommons.org/licenses/by/4.0/). 